\title{
Estudo morfológico das estruturas envolvidas no mecanismo de adesão do Limnoperna fortunei (Dunker, 1857)
}

Cláudia Lauria Fróes*

Madrith Sthel Costa Duarte**

José Roberto Tavares Branco***

\begin{abstract}
Resumo
Limnoperna fortunei é molusco bivalve invasor que causa prejuízos a sistemas de captação de água e usinas hidroelétricas. Sua presença já foi registrada nas bacias dos rios Paraná, Paraguai, Uruguai e Lago Guaíba. No presente trabalho, foi realizado um estudo morfológico das estruturas de adesão desta espécie invasora. Os estudos mostraram que o pé do Limnoperna fortunei é formado por um tecido de preenchimento com diferentes tipos celulares envolvidos nos mecanismos de adesão e locomoção. Foi verificada a presença de inúmeras vilosidades, pêlos e muco em toda a superfície externa do pé, o que aumenta a superfície de contato e conseqüentemente a adesão ao substrato. 0 bisso do Limnoperna fortunei é constituído por um eixo principal do qual partem filamentos secundários e é produzido por uma região formada por vários canalículos que conduzem a secreção adesiva até o exterior. $O$ ponto de projeção do bisso no corpo do mexilhão dourado é uma região reforçada por fibras de colágeno, o que mantém o bisso fortemente aderido ao corpo animal.
\end{abstract}

Palavras-chave: Limnoperna fortunei. Histologia. Mexilhão dourado. Adesão.

\section{Introdução}

O Limnoperna fortunei (Dunker, 1857) é um molusco bivalve invasor conhecido como mexilhão dourado. Adapta-se facilmente a diferentes habitats (Darrigran \& Pastorino, 1995). Dentre os impactos ambientais e econômicos causados pelo L. fortunei, destacam-se o efeito sobre a comunidade fitoplanctônica e a ciclagem de nutrientes; a competição com outros animais nativos que se alimentam de partículas em suspensão; a obstrução das tubulações de estações de tratamento, reservatórios, barragens e outras instalações que são prejudicadas pelo crescimento descontrolado do mexilhão dourado (Darrigran \& Pastorino, 1995; Darrigran \& Drago, 2000).

Diversas pesquisas têm sido realizadas no intuito de investigar materiais e revestimentos, com base na engenharia de superfícies, com potencial de utilização no controle das incrustações do mexilhão dourado em plantas industriais, principalmente em unidades geradoras de energia (Bergmann, et al., 2010). Mas ainda são escassos estudos da capacidade de incrustação do Limnoperna fortunei em diversos materiais.

De acordo com Brandy (2001), a maioria dos mexilhões se fixa ao substrato através de um conjunto de fibras (filamentos) denominado bisso. Esses filamentos são produzidos a partir de glândulas localizadas no pé muscular do animal. O pé muscular dos mexilhões é de extrema importância para a adesão dos mesmos, pois é capaz de sondar o substrato determinando o local da fixação.

As estruturas internas e externas do mexilhão azul (Mytilus edulis) e do mexilhão Perna perna, incluindo algumas ligadas aos mecanismos de adesão a substratos, já foram descritas (Kellog, 1915; White, 1937; Abbud, 1969; Narchi \& Bueno, 1997; Wiegemann, 2005; Silverman \& Roberto, 2007). Porém ainda pouco se sabe sobre o mexilhão invasor Limnoperna fortunei. Apesar dos mexilhões geralmente apresentarem estruturas e mecanismos de adesão com características comuns, é necessário estudos específicos para cada espécie. 
Este trabalho teve por objetivo identificar e caracterizar estruturas envolvidas no mecanismo de adesão do Limnoperna fortunei, já que a bibliografia a respeito é escassa. O conhecimento das estruturas envolvidas no mecanismo da adesão é de extrema importância para o controle da espécie. Através do conhecimento destas estruturas, podem ser propostas maneiras mais eficientes de impedir ou dificultar a adesão do mexilhão a substratos.

\section{Material e Métodos}

Exemplares de Limnoperna fortunei foram coletados nas margens do rio Guaíba, em Porto Alegre, Rio Grande do Sul, e levados para o laboratório de ecotoxicologia, cultivo de macrorganismos, do Setor de Recursos da Água do Centro Tecnológico de Minas Gerais (CETEC). O estudo foi realizado dentro de procedimentos de biossegurança estabelecidos para o cultivo e a manutenção desta espécie invasora (Campos et al., 2003).

Os exemplares de Limnoperma fortunei foram mantidos em aquários de 20 litros, em média 500 indivíduos por aquário com água declorada e aeração contínua. A água do cultivo era trocada três vezes por semana, para evitar o acúmulo de excretas. Organismos mortos eram retirados diariamente do cultivo. A temperatura da água foi mantida próximo dos $25^{\circ} \mathrm{C}$. Usou-se alimentação à base da alga Selenastrum capricornutum (Printz, 1914) e ração de peixe com teor protéico maior que $40 \%$ dissolvida em água destilada. O comportamento dos mexilhões foi observado e registrado diariamente, três horas por dia, durante seis meses.

O preparo das lâminas com os tecidos a serem estudados foi realizado segundo as técnicas clássicas de histologia de modo a preservar sua estrutura original. 0 preparo das lâminas obedeceu às seguintes etapas: fixação dos tecidos, desidratação, inclusão, microtomia (corte em fatias finas), coloração e montagem de lâminas.

Foram escolhidos aleatoriamente 50 exemplares de Limnoperna fortunei. Esses foram dessecados e suas estruturas fixadas em formol 10\%. A fixação é importante, pois paralisa o metabolismo celular e preserva as estruturas do tecido. Além disso, evita a autólise celular, impede a proliferação de microorganismos e leva ao endurecimento do tecido para que resista aos tratamentos posteriores.

Após a fixação, os tecidos foram desidratados, uma vez que a água presente nos tecidos não é miscível em substâncias apolares como a resina utilizada na inclusão (próxima etapa). A desidratação foi feita através de imersão dos tecidos em uma bateria de soluções alcoólicas em concentrações graduais e crescentes (70\%, $80 \%, 90 \%$ e álcool absoluto). O tempo de imersão em cada concentração alcoólica foi de 30 minutos.

A inclusão foi feita utilizando um tipo de resina plástica, o glicol metacrilato, que proporciona proteção, consistência e uniformidade ao material, facilitando sua microtomia (corte).

Para a inclusão no glicol metacrilato, os tecidos foram infiltrados com uma resina de infiltração por uma noite e então incluídos nos moldes contendo as resinas ainda líquidas. Após algumas horas, as resinas endurecem. Após endurecimento, obtêm-se blocos de resinas contendo o fragmento de tecido em seu interior. Os blocos serão a partir desta etapa levados para a microtomia e consequente obtenção das secções, que serão coletadas em lâminas de vidro.

Foram feitos cortes histológicos de diversas estruturas do mexilhão dourado. Os cortes foram feitos seguindo a orientação mostrada na Figura 1.

Figura 1. Plano de corte aplicado para a preparação das lâminas utilizadas no estudo histológico.



Fonte: elaboração própria. 
Os cortes de tecidos são incolores. A coloração visa contrastar as estruturas teciduais. A ação da maioria dos corantes se baseia na interação entre os radicais ácidos ou básicos dos elementos químicos dos mesmos com os dos tecidos.

As lâminas foram coradas utilizando as seguintes técnicas de coloração:

1) HE (Hematoxilina-Eosina): é a principal técnica de coloração de tecidos para estudos histológicos. São corantes adequados para evidenciar características estruturais. Através dessa coloração, podemos diferenciar porções basófilas e acidófilas do tecido estudado. A hematoxilina é basófila (possui afinidade por substâncias básicas), sendo assim, ela costuma corar o núcleo e o retículo endoplasmático rugoso, que são locais onde há grande quantidade de proteínas básicas devido ao grupamento amina. A hematoxilina cora geralmente em azul. Já a eosina é acidófila, possui afinidade por substâncias ácidas, costuma corar citoplasma, fibras colágenas e outras substâncias ácidas das células. A eosina geralmente cora as em vermelho ou rosa.

2) PAS (Periodic Acid-Schiff): essa técnica de coloração permite determinar a presença de polissacarídeos. É possível visualizar polissacarídeos simples ou associados a proteínas.

3) Azul de toluidina: esse tipo de coloração permite distinguir regiões ácidas de regiões básicas e, consequentemente, diferentes tipo celulares.

Depois de prontas, as lâminas foram analisadas através da microscopia óptica no laboratório de microscopia do setor SAA do Centro Tecnológico de Minas Gerais. Foram utilizados os seguintes aumentos para análise microscópica: 40x, 100x.

Alguns filamentos do bisso foram separados e analisados através da microscopia eletrônica de varredura para verificação da estrutura superficial. Essa análise foi realizada no Centro de Desenvolvimento de Tecnologia Nuclear (CDTN), onde foram preparadas e metalizadas com banho de ouro.

\section{Resultados e Discussão}

A formação dos filamentos do bisso do L. fortunei é muito parecida com a descrita por Narchi \& Bueno (1997) para o mexilhão Perna perna. Primeiramente o mexilhão toca várias vezes o substrato com o pé, em um comportamento exploratório, e, a seguir, aplica a face ventral no substrato. A região produtora do bisso elimina, então, lentamente, uma substância líquida pastosa de cor amarelada, que é pressionada para o sulco ventral através de movimentos musculares do pé e do corpo do animal (Figura 2).

A substância pastosa de cor amarelada irá preencher todo o sulco ventral do pé chegando até a cavidade terminal, onde é forçada contra o substrato. O pé, então, é retirado lentamente, liberando o filamento contido no sulco.

Figura 2. Exemplar do Limnoperna fortunei em comportamento exploratório.

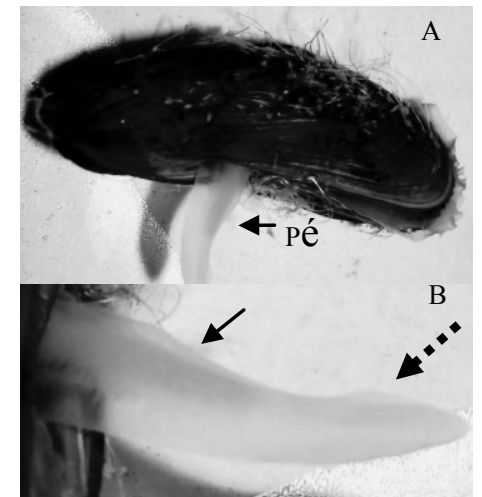

A: pé sondando o substrato se preparando para iniciar o processo de fixação; B: detalhe do pé mostrando o sulco ventral (seta tracejada) e a substância líquida pastosa de cor amarelada (seta contínua).

Fonte: elaboração própria. 
As Figuras 3A e 3B nos permite ter uma visão geral das estruturas envolvidas no mecanismo de adesão, bem como sua localização no corpo do animal. A Figura $3 \mathrm{~A}$ representa um corte longitudinal corado por azul de toluidina. O pé está localizado acima de um tecido muscular (M1). Próximo da base do pé podemos observar a presença da região produtora do bisso, região de projeção dos filamentos do bisso e massa visceral (MV). Também mostra a localização de outros tecidos musculares, como os músculos adutores da concha (M2) e o músculo M3.

Já a Figura 3B mostra a morfologia externa de um exemplar de mexilhão dourado com as valvas abertas expondo as seguintes estruturas: pé, região de projeção dos filamentos do bisso, filamentos do bisso e massa visceral.

Figura 3. Fotomicrografia do mexilhão dourado Limnoperna fortunei (magnitude 6x 2.0).

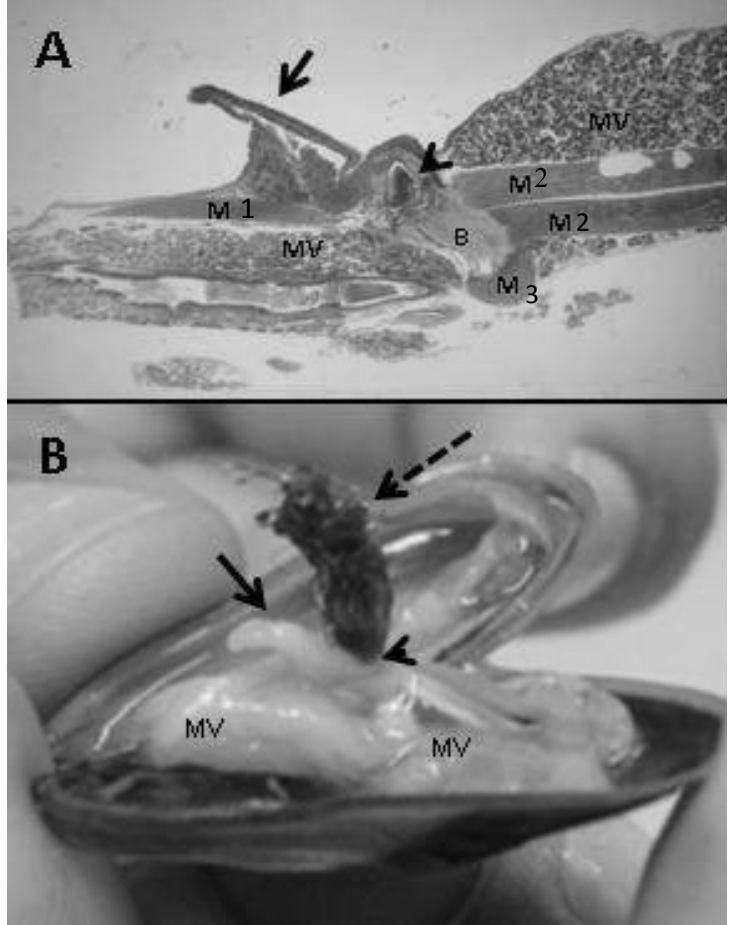

A: Corte longitudinal corado por azul de toluidina: Pé (seta contínua); Região produtora do bisso (B); massa viceral (MV); Músculos (M1 e M3); Músculos adutores da concha M2; Região de projeção dos filamentos do bisso (cabeça de seta). B: Exemplar do mexilhão dourado com as valvas abertas: Filamentos do bisso (seta pontilhada), pé (seta contínua) e massa visceral (MV).

Fonte: elaboração própria.

A Figura 4 mostra cortes histológicos longitudinais da porção distal do pé do Limnoperna fortunei. As Figuras 4A e 4B mostram cortes corados com hematoxilina-eosina (HE). Na Figura 4A podemos identificar a presença de um tecido de preenchimento formado por duas regiões com padrões distintos de coloração, claro (rc) e escuro (re), grande quantidade de núcleos celulares (n), e a presença de uma fina camada de células epidérmicas justapostas (e) em toda a superfície externa, além de vilosidades. Na Figura 4B podemos ver um detalhe das vilosidades que estão presentes em toda superfície do pé e das células epidérmicas justapostas (e). 
Figura 4. Fotomicrografia de cortes histológicos longitudinais do pé do mexilhão dourado Limnoperna fortunei.
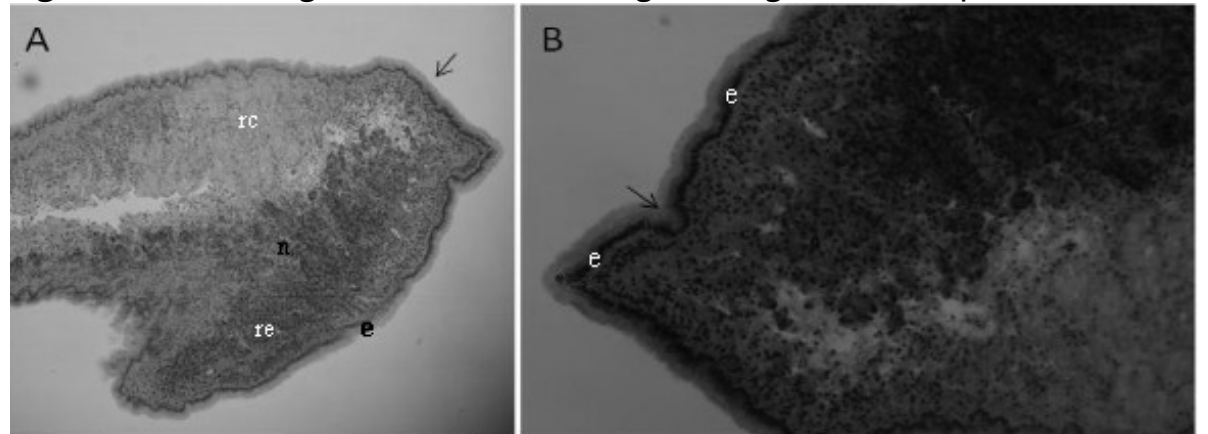

A (magnitude $100 \times$ 2.0), B (magnitude 200x). A e B cortes corados por Hematoxilina-eosina (HE) que mostram a porção distal do pé revestido por fina camada de células epidérmicas justapostas (e), tecido de preenchimento com duas regiões com padrões de coloração distintos, claro (rc) e escuro (re), grande quantidade de núcleo (n), vilosidades (seta contínua) e pêlos (seta pontilhada).

Fonte: elaboração própria.

Nas Figuras 5A e 5B visualizamos cortes corados por PAS, o que indica presença de resíduos de carboidratos (muco), região escura, principalmente nas vilosidades. Verificamos a presença de células epidérmicas justapostas e de cisternas no tecido de preenchimento. As células que formam as vilosidades do pé do L.fortunei ficaram muito marcadas pela coloração PAS (PAS positiva). Isso sugere produção de muco (proteína + polissacarídeo) nessa região. Além das vilosidades e pêlos, o pé do mexilhão dourado também produz muco, o que aumenta ainda mais o seu poder de adesão a substratos. Além disso, como podemos verificar na Figura 5B, a presença das cisternas (c) é importante para espalhar o muco produzido por todo o pé do Limnoperna fortunei, auxiliando sua fixação aos substratos.

Figura 5. Fotomicrografia de cortes histológicos longitudinais do pé do mexilhão dourado $A$ (magnitude 100x) e B (magnitude 250x).

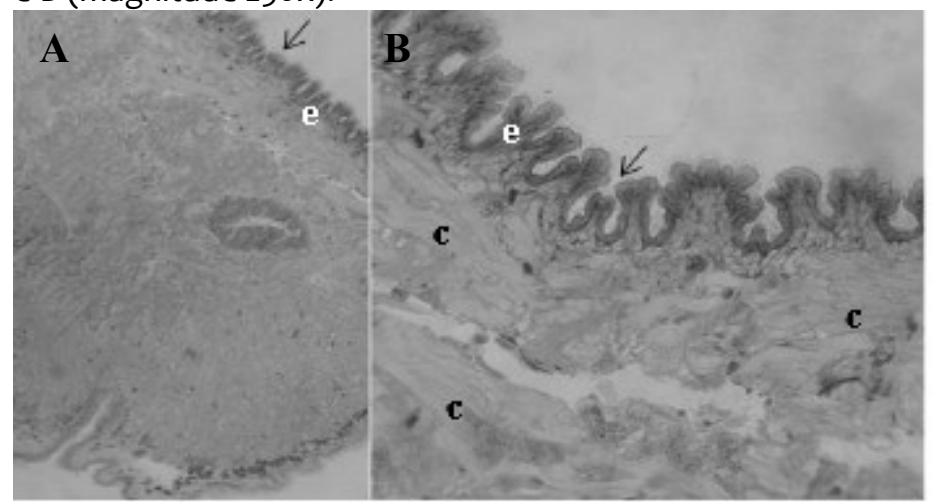

Cortes corados por PAS que indica presença de resíduos de carboidratos (parte escura), vilosidades (seta contínua), células epidérmicas (e) e presença de cisternas no tecido de preenchimento (c).

Fonte: elaboração própria.

As Figuras 6A, 6B e 6C, cortes corados por azul toluidina, confirmam o padrão de marcação identificado por HE (duas regiões com padrões distintos de coloração: claro e escuro) e a presença das células epidérmicas, vilosidades e pêlos na superfície. 
Figura 6. Fotomicrografia de cortes histológicos longitudinais do pé do mexilhão dourado A (magnitude 250x), B (magnitude: 100x) e C (250x).

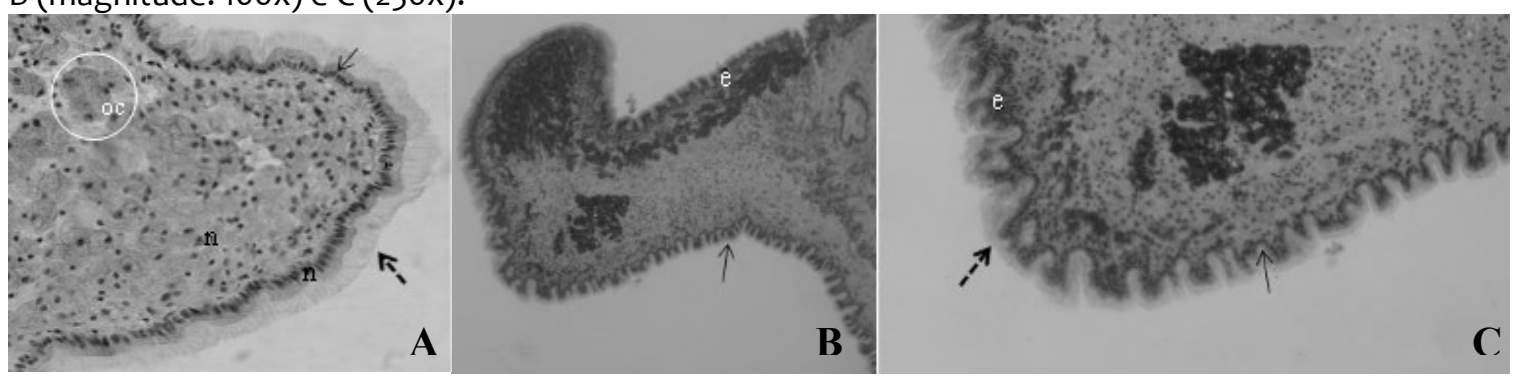

Cortes corado por azul toluidina confirmando o padrão de marcação identificado por HE, grande quantidade de núcleo (n), camada de células epidérmicas justapostas (e), vilosidades (seta contínua), presença de pêlos cobrindo as células epidérmicas (seta pontilhada) e presença de organizações celulares (oc).

Fonte: elaboração própria.

De acordo com Brandy (2001), os mexilhões possuem um pé muscular de extrema importância para a adesão, pois é capaz de sondar o substrato determinando o local da fixação. Porém, durante o estudo histológico do pé, não se verificou a presença de um tecido muscular tradicional constituído de fibras de actina e miosina. As observações histológicas sugerem que o pé do Limnoperna fortunei seja constituído por um tecido de preenchimento com duas regiões de padrões distintos de coloração (região clara e região escura) e com grande quantidade de núcleos celulares (Figuras 4A, 4B e 6A). Esse fato indica que o pé do mexilhão dourado seja formado por diferentes tipos celulares. As células do tecido de preenchimento parecem se organizar em pequenas unidades com características contráteis que devem ser as responsáveis por contrações brandas que ocorrem no pé e que auxiliam o animal a se locomover e sondar substratos. Essas células também seriam responsáveis pelos movimentos musculares do pé que ajudam a pressionar a substância líquida pastosa de cor amarelada, produzida na região produtora do bisso para o sulco ventral do pé, auxiliando desta maneira na produção dos filamentos do bisso (Figura 2).

No pé do Limnoperna fortunei, verificou-se a presença de uma fina camada de células epidérmicas justapostas em toda a superfície externa, além de vilosidades (Figuras 4, 5 e 6). Estas aumentam a superfície de contado do pé do animal com o substrato possibilitando uma melhor adesão. Na extremidade das vilosidades, foi detectada a presença de milhares de pelos (ver Figuras 4A e 6A). Esses pelos aumentam ainda mais a superfície de contato, tornando a adesão mais eficaz.

A superfície do pé coberta por pelos do L. fortunei é muito parecida com a do mexilhão Mytilus edulis, estudado por White (1937) apud Narchi e Bueno (1997). Narchi e Bueno (1997) não detectaram a presença de pêlos na superfície do pé do mexilhão Perna perna.

Figura 7 A e B. Fotomicrografia de um corte histológico longitudinal corado por azul de toluidina (magnitude 100 x 2.0) mostrando a presença de um músculo na base do pé do Limnoperna fortunei (M1) e visto em maior aumento em B (magnitude $200 \times 2.0$ ).

Fonte: elaboração própria.

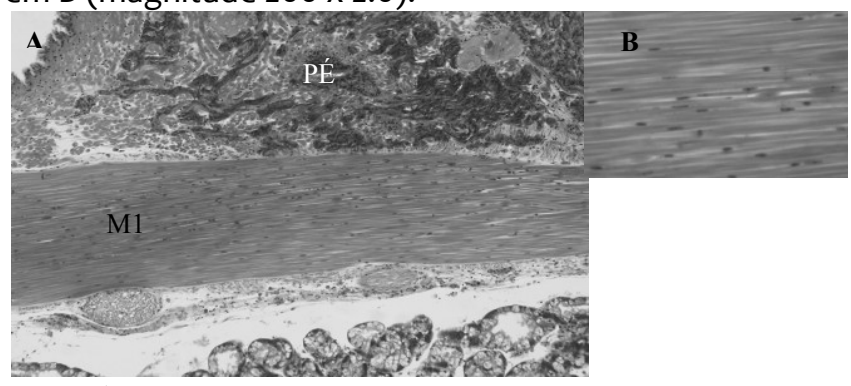

O mecanismo de adesão do L.fortunei, envolvendo pelos, parece bastante com o descrito por Autum et al (2002) para as lagartixas. As lagartixas possuem pelos microscópicos queratinizados que 
cobrem suas patas e são responsáveis pela adesão das mesmas a substratos. As lagartixas se aderem a qualquer tipo de substrato e possuem um mecanismo de adesão versátil e eficaz.

As Figura 7A e 7B mostram um corte longitudinal da base do pé do Limnoperna fortunei corado com azul de toluidina. Esse corte exibe o músculo M1, visto em detalhe em 7B. Esse tecido presente na base do pé do mexilhão dourado é um músculo com aspecto morfológico similar ao tecido muscular constituído de fibras de actina e miosina. Provavelmente é o responsável pelas maiores contrações do pé, como, por exemplo, esticá-lo para o exterior da concha durante a sondagem do substrato ou recolhê-lo para o interior da concha.

Brandy (2001) afirma que o bisso dos mexilhões é produzido a partir de glândulas localizadas na base do pé. Porém, nossos estudos mostraram que o bisso do Limnoperna fortunei não é produzido por uma glândula propriamente dita, e sim por uma região produtora formada por canalículos que conduzem a secreção adesiva (Figuras 8A, 8B e $8 \mathrm{C}$ ). Sugerimos que o músculo (M3) (Figura 8A) participa da eliminação da secreção adesiva formadora do bisso ao provocar uma contração dos canalículos e assim transportar essa secreção. Os canalículos convergem toda a substância adesiva produzida para um único ponto, onde ocorre a exteriorização da substância adesiva, que forma o bisso (Figura 7A).

Figura 8. Fotomicrografia de cortes histológicos longitudinais da região produtora do bisso do mexilhão dourado Limnoperna fortunei corados por azul de toluidina.

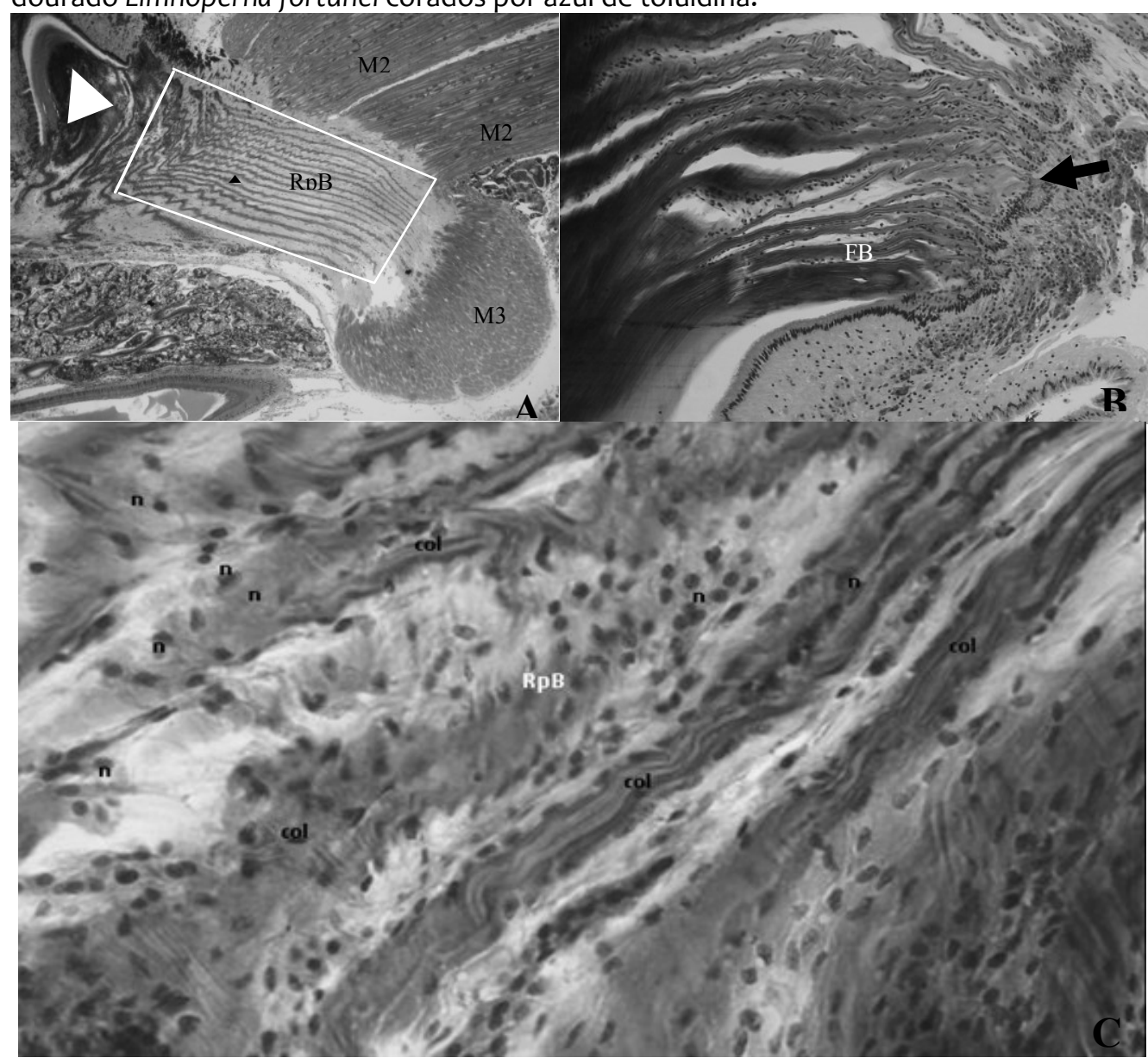

A (magnitude 40 x 2.0): visão geral da região produtora do bisso: Tecido muscular dorsal (M1), músculo adutor da concha $\left(\mathrm{M}_{2}\right)$, Região produtora do bisso $(\mathrm{RpB})$ contendo vários cisternas $(\downarrow)$ região de projeção do bisso (seta). B (magnitude 100 x 2.0): ponto de projeção do bisso (seta) e filamentos do bisso (FB) responsáveis pela adesão do mexilhão ao sủbstrato. C. (magnitude 400 x 2.0): região produtora do bisso (RpB) evidenciando núcleos celulares $(\mathrm{n})$ e filamentos tipo-colágeno (col) característicos. 
Segundo Carrington (2002) os filamentos do bisso são formados por fibras de colágeno. Este fato pôde ser observado neste estudo como mostra a Figura 3A e 3B que identifica o ponto de projeção do bisso no corpo do mexilhão dourado. É uma região reforçada por fibras de colágeno, o que mantém o bisso fortemente aderido ao corpo do animal. Figura $8 \mathrm{C}$ mostra um detalhe da região produtora do bisso (RpB), evidenciando os núcleos celulares (n) e os filamentos tipo-colágeno (col) sendo formados e que juntamente com a secreção adesiva formarão o bisso.

A Figura 9 mostra cortes histológicos longitudinais da região produtora do bisso do mexilhão dourado Limnoperna fortunei corado por PAS. Na Figura 9A pode-se visualizar a região produtora do bisso (RpB), o tecido muscular dorsal (M3), a região de transição entre M1 e RpB (setas pontilhadas). A região de transição entre $\mathrm{M} 3 \mathrm{e} \mathrm{RpB}$ (indicada pelas setas) foram fortemente marcadas por PAS.

Na Figura 9B podemos ver o ponto de projeção/inserção do bisso (seta), formação das fibras do bisso e cisternas, todos fortemente marcados.

A região dos canalículos foi fortemente corada (PAS positivo), indicando grande produção de muco, o que reforça a teoria desta região ser a produtora do bisso (Figuras 9A e 9B).

Figura 9. Fotomicrografia de cortes histológicos longitudinais da região produtora do bisso do mexilhão dourado Limnoperna fortunei corado por PAS.

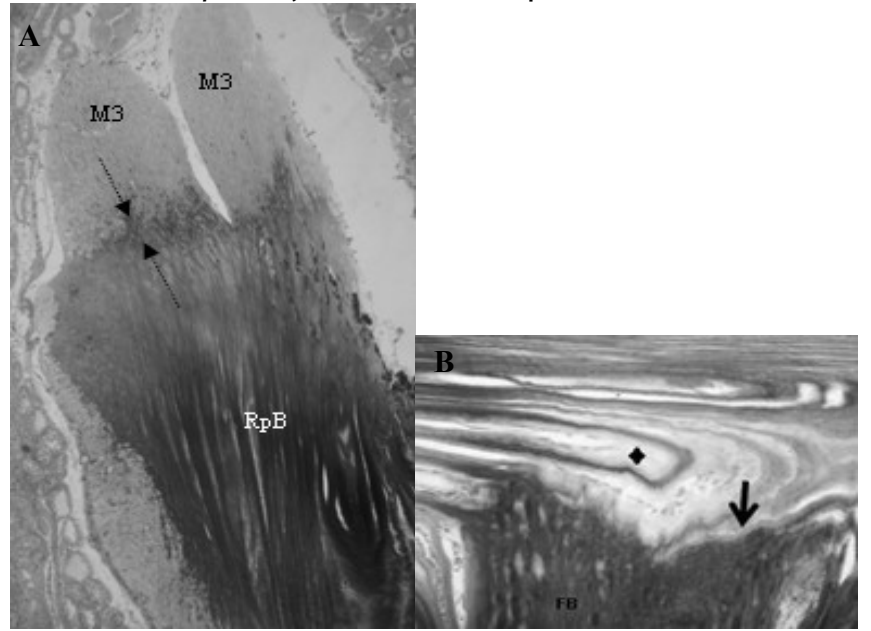

$A$ (magnitude $40 \times 2.0)$ : Visão da região produtora do bisso $(R p B)$, tecido muscular dorsal $(M 3)$, região de transição entre $M_{3}$ e RpB (setas pontilhadas), fortemente marcadas. B (magnitude $100 \times 2.0$ ): Ponto de projeção/inserção do bisso (seta), formação das fibras do bisso (FB) e cisternas ( $\bullet$ ).

O bisso do Limnperna fortunei, assim como o bisso do mexilhão Perna perna estudado por por Narchi \& Bueno (1997), é constituído por um eixo principal (Figura 10) do qual parte grande número de filamentos secundários. Tal fato pôde ser visualizado na Figura 10, na qual se observa um filamento central de onde partem os demais filamentos do bisso.

Figura 10. Foto micrografia tirada em microscópio eletrônico de varredura mostrando o eixo principal do bisso (EP) com diversos filamentos secundários (setas).

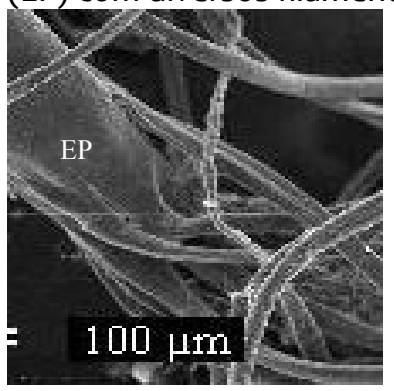

Fonte: elaboração prática. 


\section{Conclusão}

O pé do Limnoperna fortunei é formado por um tecido de preenchimento com diferentes tipos celulares que parecem se organizar em pequenas unidades com características contráteis que devem ser as responsáveis por contrações brandas que ocorrem no pé e que auxiliam a locomoção do animal.

Em toda a superfície externa do pé, verificamos a presença de inúmeras vilosidades e pelos, que aumentam a superfície de contato e consequentemente a adesão. As células epidérmicas justapostas que formam as vilosidades produzem um muco (proteína + polissacarídeo), aumentando ainda mais a capacidade de adesão do pé ao substrato.

Verificou-se a presença de um tecido muscular na base do pé do Limnoperna fortunei. Esse tecido é responsável por esticar e retrair o mesmo.

O bisso do Limnoperna fortunei parece ser produzido por uma região formada por vários canalículos que conduzem a secreção adesiva até o exterior.

Os canalículos convergem toda a substância adesiva produzida para um único ponto onde ocorre a exteriorização da mesma formando então o bisso. O ponto de projeção do bisso no corpo do mexilhão dourado é uma região reforçada por fibras de colágeno, o que mantém o bisso fortemente aderido ao corpo do animal.

O Limnoperna fortunei possui um comportamento exploratório: o pé toca o substrato várias vezes até determinar o melhor local para a sua fixação. A seguir aplica a face ventral do pé sobre o substrato. A região produtora do bisso elimina, então, lentamente, uma substância líquida pastosa de cor amarelada, que é pressionada para o sulco ventral através de movimentos musculares do pé e do corpo do animal. Essa substância pastosa de cor amarelada preenche todo o sulco ventral do pé, chegando até a cavidade terminal do mesmo, onde é forçada contra o substrato, formando o disco adesivo. O pé, então, é retirado lentamente, liberando o filamento contido no sulco.

o bisso do Limnoperna fortunei é constituído por um eixo principal do qual partem vários filamentos secundários.

\section{Morphological study of the structures involved in the adhesion mechanism Limnoperna fortunei (Dunker, 1857)}

\section{Abstract}

The Limnoperna fortunei is a freshwater bivalve invader that has caused damage to water catchment systems and hydroelectric plants. His presence has already been recorded in the basins of the rivers Parana, Paraguay, Uruguay and Guaíba Lake. In this study, we performed a morphological study of the structures involved in the adhesion mechanism of this invasive species. These studies demonstrate that the foot of Limnoperna fortunei is formed by a woven fill cell type related with adhesion and mobility mechanisms. The occurrence of numerous villi, hair and mucus across the outer surface of the foot increase the contact with the surface and consequently the adhesion to the substrate. The byssus the Limnoperna fortunei comprises a main axis which run side filaments and is produced by a region formed by several canaliculi leading to secretion adhesive to the outside. The projection point of the byssus in the body region is reinforced by fibers of collagen, which keeps the byssus strongly adhered to the animal body.

Keywords: Limnoperna fortunei. Histology. Mussel. Adhesion. 
***Fundação Centro Tecnológico de Minas Gerais (CETEC),jrtbranco@yahoo.com.br

\section{Referências bibliográficas}

ABBUD, L. 1969. Fisiologia e farmacologia dos músculos de Mytilus perna. Bolm. Fac. Fitos. Ciên. Univ. S. Paulo 324. Zool. BioI. Mar. 26: 113-1180.

AUTUMN , K; SITTI, M; LIANG, Y. A, PEATTIE, A. M; WENDY R. SPONBERG, H. S; KENNY, T. W; FEARING, R; ISRAELACHVILI, J. N., AND FULL R. J. Evidence for van der Waals adhesion in gecko setae. PNAS Aug 27, 2002

BERGMANN, C.P; Mansur, M.C.D; Pereira, D; Bergonci, P.E.A; Santos, C.P. Dos; Basegio, T; Vicenzi, J; Santos, S.C.A. 2010. Avaliação de materiais e revestimentos para controle de incrustações do mexilhão dourado Limnoperna fortunei (Dunker, 1857). Biotemas, 23: 87-100.

BRANDY, R. F. JR., A fracture mechanical analysis of fouling release from nontoxic antifouling coatings, Progress in Organic Coatings, v.43, p.188-192, 2001.

CAMPOS, M.C.S.; RUCKERT, G.; ROLLA, M.E. Nota sobre procedimento de segurança no cultivo e manutenção de Limnoperna fortunei (Dunker,1857) em laboratório. In: IX Congresso Brasileiro de Liminologia, Juiz de Fora, 2003.

DARRIGRAN, G. \& Pastorino, G. The recent introduction of a freshwater Asiatic bivalve, Limnoperna fortunei (Mytilidae) into South America. Veliger 38(2): 171-175, 1995.

DARRIGRAN G. e de DRAGO I. E. Invasion of the exotic freshwater mussel Limnoperna fortunei (Dunker, 1876) (Bivalvia : Mytilidae) in South America. Nautilus 114 (2): 69-73, 2000.

KELLOGG, l.L. 1915. Ciliary mechanisms of Lamellibranchs with descriptions of anatomy. Jour. Morph. 26 (4): 625-701.

NARCHI, W.; BUENO, M.S.G. Anatomia Funcional de Perna perna (Linné) (Bivalvia, Mytilldae) Revta bras. ZoaI. 14 (1): 135 -168, 1997

SILVERMAN, G.S; ROBERTO, F.F. Understanding Marine Mussel Adhesion Biological Systems Department, Idaho National Laboratory, Idaho Falls, Idaho 83415, USA Received: 7 March 2007 / Accepted: 5 September 2007 / Published online: 8 November 2007.

WHITE, K.M. 1937 - Mytilus. Liverpool Memoires Riol. Comm. 7: 1-117.

WIEGEMANN M. Adhesion in blue mussels (Mytilus edulis) and barnacles (genus Balanus): Mechanisms and technical applications. Aquatic Sciences, 67: 166-176, 2005. 